\title{
DIVERSITY AND IMPACT OF NATIONAL CULTURE ON UNDERGRADUATE STUDENTS' LEARNING STYLES
}

\author{
Nedka Dimitrova*
}

\begin{abstract}
With the rapid process of globalisation since the beginning of the $21^{\text {st }}$ century, education and businesses face the challenge of intensifying multiculturalism. Higher education institutions in Europe are expected to play a particularly important role in facilitating this process. The purpose of this study is to examine the relationship between national culture and the preferred learning styles in the context of Higher Education as well as to find out specific patterns of cultural influence on individual learning preferences. It aims to identify practical implications for teachers and trainers in a culturally diverse environment. The empirical investigation was based on D. Kolb's Experiential learning theory (ELT, Kolb 1984) and G. Hofstede's (1980) work on National and Organisational dimensions of culture.
\end{abstract}

Key words: Kolb, learning styles, Hofstede, cultural dimensions, cultural impact, higher education

\section{Introduction}

Students' learning success is closely connected with individual culture, family and socioeconomic background and educators agree upon the belief that the context in which people are brought up is particularly important for personal development. Understanding the role of cultural values and improving cultural sensitivity by educators is crucial for establishing a positive and encouraging learning environment (Cohen et al. 2004).

Do cultural differences have an influence on types of thinking, styles of learning and communicating or these are only culturally stereotyped perceptions?

This research aims to provide evidence for the link between the preferred individual learning styles and the national culture, as well as to make useful suggestions for Higher education instructors, students, and managers, who are interested in taking the conclusions into account. D. Kolb's Experiential Learning

\footnotetext{
* Senior Lecturer of Business English and Communication skills, Department of Modern Education, Varna University of Mangement, Varna, Bulgaria, e-mail: nedka.dimitrova@vumk.eu
} 
Theory (1984) was used to find out individual learning preferences and to suggest interpretations of learning styles through the idea of experiential learning, which integrates four different abilities - learning from concrete experience, reflective observation, abstract conceptualisation and active experimentation. Experiential Learning Theory (ELT, Kolb 1984) argues that learning is "the process whereby knowledge is created through the transformation of experience. Knowledge results from the combination of grasping and transforming experience" (Kolb, cited in Joy, Kolb 2009: 4).

G. Hofstede's (1980) cultural dimensions theory provides a fundamental base for cultural comparison of individual learning styles with the concept of a set of several dimensions, characterizing countries by Power Distance (PDI), Masculinity (MAS), Uncertainty Avoidance (UAI), Individualism (IDV), Longterm Orientation (LTO), and Indulgence (IND). According to Hofstede, culture is " ... the collective programming of the mind that distinguishes the members of one group or category of people from others" (Hofstede et al. 2010: 5) and cultural differences can have a meaning only through comparison.

A commonly used method in the field, One-way analysis of variance (ANOVA) was used to determine if there exist statistically significant differences between the means of the cultural dimensions and the learning style variables.

\section{Learning styles and Kolb's Experiential Learning Theory (ELT)}

The Experiential Learning Theory (Kolb 1984) suggests a learning model, which is a commonly used instrument for evaluation of individual learning styles and "the clearest exposition of the concept of experiential learning" so far, according to Smith's 1992 study (cited in Sheehan, Kearns 1995: 10). The model represented by ELT relies on two dialectically bound modes of grasping experience: Concrete Experience (CE) and Abstract Conceptualisation (AC) and two modes of transforming experience: Reflective Observation (RO) and Active Experimentation (AE). The main principle of the ELT is expressed through a four-stage cycle in which the concrete experience gives ideas for reflections and observations. The assimilated reflections are transformed into abstract concepts leading to action.

The concept of Kolb's theory is based on the differences in the preferences each individual possesses as a combination of four dialectic modes. Thus the four main styles of learning are identified as Diverging, Assimilating, Converging and Accommodating and these can be applied as a starting point for better understanding of the individual approaches to learning.

Kolb argues that Divergers prefer concrete experience to grasp information and reflective observation to transform it. They tend to feel and watch in the process of learning and are well able to look at a situation from different perspectives. Concise and logical with a focus on concepts, the Assimilators 
demand clear explanations rather than practical application. They are able to structure and organise logically a broad range of theoretical information and do not demonstrate an interest in communication with other people. Convergers are best at finding solutions for technical tasks using their own previous learning experience. Interpersonal issues and social aspects are not in the focus of Convergers. Accommodators are more likely to rely on intuition rather than logic as well as on other people's analysis and information. Applying practical approach through personal experience and risk-taking makes people with this preference most suitable for carrying out plans and activities requiring initiative.

\section{Culture as a mental programming in education context}

People carry with themselves their own personal patterns of feeling, thinking and acting, which are learnt throughout childhood. Learning a new thing in life of adults requires unlearning of the subconsciously adopted models. Hofstede (2010) calls these mental programs that are based on the social environment in which a person grew up and gathered experience. This mental software is actually expressed through culture, which in its social anthropology meaning, combines all those patterns of acting, feeling and thinking. "Culture consists of the unwritten rules of the social game" (Hofstede et al. 2010: 4). Hofstede's (1980) cultural classification typology has suggested six dimensions so far, through which cultures can be compared.

Power Distance (PDI) In higher PDI societies the teacher is expected to be the highest authority and to know all the truth. Students are not encouraged to make their own decision and the training and teaching approach is expected to be more teacher-centred. Low PDI cultures do not tolerate concentration of power and expect to make their own decisions. Learners from low PDI societies will prefer more personal initiative and involvement through a hands-on approach.

Individualism vs. Collectivism (IDV). The main approach in collectivist cultures to training and education is teacher-centred as an expression of respect to authority and collectivist values. The individualist classroom students expect to be treated as separate individuals, with equal rights and opportunities to learn through practice and mistakes. (Hofstede et al. 2010).

Masculinity vs. Femininity (MAS) According to Hofstede (2001), masculine societies strive for competition and achievement. Academic performance is rewarded, students get motivated by concrete results. More modest and less assertive cultures are defined as feminine, they are driven by consensus and care for the members of the group, whilst masculine ones are motivated by individual achievement and performance. 
Uncertainty Avoidance (UAI) Jaju et al. (2002) associate high UAI students with being "more comfortable with structured learning situations and concerned with concrete and right answers. Kolb and Kolb (2005) emphasise on the preference for active experimentation in societies with a lower degree of UAI. Reflective observation, according to Barmeyer (2000), is more likely to have an association with a high level of uncertainty.

Long-Term Orientation (LTO) Hofstede (1980) suggested that short-term oriented societies value freedom, achievement and care of oneself. Analytical thinking and consistency of thought are a priority with a focus on the present result. Long-term cultures are focused on learning, adaptiveness, and self-discipline. Thinking of the abstract future rather than the current moment has an influence on the concept of success and profit.

\section{Previous research on learning styles in cultural context}

Lum, Bradley, and Rasheed (2011) found a strong relationship between high collectivist cultural values and orientation to reflective observation of professionals in nursing, pharmacy and teaching. Japanese managers, Australian students and American EFL teachers, studied by Yamazaki (2005), Fridland (2002) and Hoppe (1990) were also identified as reflective learners. Joy and Kolb (2009) suggested that countries which are high in uncertainty avoidance demonstrate orientation to reflective style. Abstract conceptualisation tends to show as dominant in cultures measuring high in uncertainty avoidance, future orientation, and performance orientation. Yamazaki (2005) and Hoppe (1990) also identified a strong correlation link between the degree of uncertainty avoidance and the preference for reflective learning.

\section{Hypotheses development}

Since previous research argued that cognitive structure is influenced by cultural values, therefore, we can assume that the process of grasping and transforming experience is associated with culture. Based on this, we can hypothesise the following:

H1: a) There will be a significant difference between the cultural groups in their preference for grasping experience through Abstract conceptualisation over Concrete experience $(A C-C E)$.

b) There will be a significant difference between the cultural groups in their preference for transforming experience through Active experimentation over Reflective observation $(A E-R O)$.

Collectivism/Individualism Kolb and Kolb (2005) found that preference for working in groups in collectivist cultures is often related with active 
experimentation because of the smaller degree of personal involvement. Individualist learners tend to feel more confident with more individual tasks.

H2: Collectivism will be positively associated with a preference for grasping experience through Abstract conceptualisation.

H3: Collectivism will be positively associated with a preference for transforming experience through Active experimentation.

Power distance in formal, hierarchical cultures is related to abstract conceptualisation and concrete experience is not needed. In informal and democratic cultures, a teacher is a source of ideas, which further should be developed by the learner through concrete experience

H4: Higher Power Distance will be positively associated with a preference for grasping experience through Abstract conceptualisation.

H5: Higher Power Distance will be positively associated with a preference for transforming experience through Reflective observation.

Uncertainty avoidance is associated with new experience, which requires active engagement and experimentation of new situation as argued by Holtbrugge and Mohr (2010). In terms of transforming information, Kolb's concept accepts that higher UAI is associated with preference for reflective observation whereas low level correlates with active experimentation.

H6: Higher degree of Uncertainty Avoidance will be positively associated with a preference for grasping experience through Abstract conceptualisation.

H7: Higher degree of Uncertainty Avoidance will be positively associated with a preference for transforming experience through Reflective observation.

Masculinity vs. Femininity implies the idea of more emotional and caring approach and decision making based on feelings, which was linked with preference for concrete experience (Barmeyer 2000).

H8: Masculinity will be positively associated with a preference for grasping experience through Abstract conceptualisation.

H9: Masculinity will be positively associated with a preference for transforming experience through Reflective Observation.

Long-term orientation according to Hofstede (2001) is focussed on values related to the future, without much consideration of the present situation. This conveys the idea that long-term societies will be more reflective and abstract thinking.

H10: Long-Term Orientation will be positively associated with a preference for grasping experience through Abstract conceptualisation. 
H11: Long-term Orientation will be positively associated with a preference for transforming experience through Reflective Observation.

\section{Research Approach}

A version of the Learning Style Inventory, LSI (Kolb 1984) was distributed to an international group of 88 undergraduate students of management, enrolled in an HE institution in Bulgaria. The questionnaire consists of 10 sets of words, each of which relates to the four learning types identified by Kolb (1984). After calculating the total scores for each column (adding all scores going down), students were able to identify their individual preference for $\mathrm{CE}, \mathrm{RO}, \mathrm{AC}$, or AE. Learning style was identified through comparing the two combination scores with the cut-off points, defined by the normative group for $\mathrm{AC}-\mathrm{CE}$ at 4.3 and for $\mathrm{AE}-\mathrm{RO}$ at 5.9.

In the first part of the analysis, to find out if there exists a statistically significant difference of $\mathrm{AC}-\mathrm{CE}$ and $\mathrm{AE}-\mathrm{RO}$ means between 5 culture groups (85 cases), One-Way ANOVA was conducted and the $p$-value was compared to the significance level of $\alpha<0.05$ to test the null hypothesis, stating that all population means are equal.

In the second part of the analysis, we attempted to identify empirical evidence for an association between the learning style preferences and the cultural backgrounds of 72 cases from 19 countries. All students, the regular stream, and the Erasmus + exchange students, were undertaking similar academic modules in international management or tourism and hospitality management with an average age of 22 and a gender proportion of $61 \%$ female and 39\% male students. All countries were regrouped into bands for each of the Hofstede's dimension, in a way which allows us to combine similar country scores with no significant difference between each other.

\section{Results}

Individual learning style preferences The Divergent quadrant scores appeared to be the highest $(46.5 \%)$ of all, demonstrating a dominance of the preference for reflective approach and observation in the process of transforming information. Our results proved a main preference for the Kolb's reflective observation modality, which is associated with sensitivity, intuitive orientation and intuitive decision making. The Accommodative style of learning scored lower than the Divergent (27.3\%), however still significantly high in all groups to support the concept that management as a professional field tends to attract people with an emphasis on concrete experience and active experimentation. A relatively low preference of $16 \%$ was measured for the Assimilative style of learning, followed by $10,2 \%$ preference for the Convergent style. According to previous research, 
Southern Asia scores very high in the assimilative quadrant, which was also supported by our study.

Overall statistics model for $\boldsymbol{A C}-\boldsymbol{C E}$ and $\boldsymbol{A E}-\boldsymbol{R} O$ The overall $\mathrm{AC}-\mathrm{CE}$ means comparison between the cultural groups proved a significant difference with an $F$ value $=2.667$ and a probability less than $.05(p=.38)$ thus, supporting our hypothesis $\mathrm{HI}$ (a).The ANOVA test results of AE - RO did not prove any significant differences between the cultural groups with a roughly equal ratio of the groups' values. Hypothesis 1(b) was rejected, which leads to the idea that professional specialisation and personality traits might have stronger influence on transforming information in comparison with cultural characteristics.

\section{Impact of Individualism versus Collectivism on learning style preferences} It was found that the most individualist country band 3 in our sample demonstrated the highest mean and the lowest standard deviation on the $\mathrm{AC}$ $\mathrm{CE}$ continuum among the other clusters, which describes a greater preference for Concrete experience. As all countries in both Band 1 and Band 2 belong to highly collectivistic societies, according to Hofstede (2001), we can conclude that our Hypothesis 2 was supported ( $F$ value $=306.09$ and a probability $<$ .01). The analysis identified the Western European cluster mean (Band 3) score as the farthest located from the cut-off point of 5.9 on the AE - RO continuum. Comparative analysis of the $\mathrm{AE}-\mathrm{RO}$ shows that all values gradually decrease towards the RO mode, while the Individualism scores increase at the same time. Thus, we can conclude that our hypothesis $\mathrm{H}_{3}$ was marginally supported. ( $F$ value $=255.08$ and probability $<.01)$.

Impact of Power Distance on learning style preferences Comparison between the $\mathrm{AC}-\mathrm{CE}$ means of the bands and their standard deviations found that all means fall below the cut-off point of 4.3 demonstrating preference for concrete experience and identifying dependence on the degree of PDI in all bands. The highest measuring in PDI, Band 4 surprisingly scored second on the same mode immediately after Band 1 . All other bands followed the pattern suggested by our hypothesis $H 4$ so we can summarise that it was supported ( $F$ value $=1380.06$ and probability <.01). The exploration of the band means identified an opposite to our hypothesis mirror image of their distribution along the $\mathrm{AE}-\mathrm{RO}$ axis. Band 1 demonstrated the highest preference for reflective observation. Bands 2, 3 and 4 mean values were gradually increasing towards the mode of active experimentation, therefore, hypothesis $H 5$ proved wrong $(F$ value $=1267.66$ and probability $<.01)$, supporting a statement which was opposite to ours.

Impact of Uncertainty Avoidance on learning style preferences We found that the mean $\mathrm{AC}-\mathrm{CE}$ scores of each band were proportionally decreasing along with the increase of the UAI degree, revealing a greater preference of higher UAI countries for concrete experience - contrary to our hypothesis H6, which was rejected $(F$ value $=975.33$ and probability $<.01)$. Even though all $\mathrm{AE}-$ 
RO mean values were smaller than the cut-off point of 5.9 and closer to the mode of reflective observation, they were distributed in the way predicted in $\mathrm{H7}$, therefore, we assumed that our hypothesis was supported. ( $F$ value $=900.58$ and probability $<.01)$.

Impact of Masculinity vs. Femininity on learning style preferences We found that the most feminine Band 1 demonstrated the strongest preference for concrete experience and Band 3, the most masculine, was located closest to the axes intersection, which speaks about an inclination to switch to abstract conceptualisation in a particular context thus, our hypothesis $H 8$ about the impact of the MAS degree on the preference for AC-CE was supported. (F value $=796.62$ and probability $<.01)$. The specific pattern of the AE $-\mathrm{RO}$ means distribution was also partially supportive ( $F$ value $=683.62$ and probability $<$ .01) to our hypothesised statement in $H 9$, so we can conclude that masculinity still has a relative impact on the process of transforming information, even if it is lower than its influence on grasping information.

\section{Impact of Long-Term vs. Short-Term Orientation on learning style preferences}

The observation of the band mean values did not provide any convincing evidence of relationship between LTO and the preference for grasping information. The ANOVA analysis of variance produced a significant result, validating partially our hypothesis through significant difference for Band 2, which is not enough to support our suggested hypothesis $H 10$ ( $F$ value $=426.18$ and probability $<.01)$ therefore it must be rejected. The ANOVA analysis of the AE - RO followed an irregular pattern similar to the $\mathrm{AC}-\mathrm{CE}$ distribution. As a result we can conclude that despite the statistical validation, our hypothesis $H 11$ was rejected $(F$ value $=380.46$ and probability $<.01)$ and the LTO dimension has no direct impact on the preference for transforming experience.

\section{Discussion}

\section{The influence of cultural differences on learning preference of business management students}

Based on the results of our study, we can argue that cultural differences obviously have impact on learning and communication with a more significant influence on business management students' preference for grasping experience (AC $\mathrm{CE}$ ) in comparison with the process of transforming experience (AE - RO). The main finding from our research is that all cultural groups demonstrated a dominant preference for concrete experience and reflective observation. Therefore, the overall most characteristic style of learning was identified as Divergent, followed by the Accommodative.

Academic fields matching each of the learning styles, according to Piaget's research 1970 (cited in Montgomery, Groat 1998) illustrate the predominant 
preference for the Divergent and Accommodative styles, found in this study and the link to the professional specialisation in social science and humanities. Kolb has focused the attention on the concept that the majority of students in the same discipline are highly likely to express a similar preference for learning style, proved true in this study. The orientation towards concrete experience is driven by a willingness to deal with concrete interpersonal situations, involving human abilities of sensitivity and empathy for other people's emotions. These traits predispose leadership skills and a strong ability to work in different countries and in a multi-cultural environment, especially in the field of business management.

\section{The effect of cultural dimensions on students' preference for learning styles}

A higher degree of power distance was expected and identified in the education settings of the cultural clusters in our study sample, maintaining an orientation towards concrete experience and reflective observation along with the decrease in the degree of power distance. This was opposite to Barmeyer's (2000) assumption that students from low power distance societies will be more likely to participate in group activities and to search for feedback, as well as to Holtbrügge and Mohr's (2010) findings, associating the increased power distance with the likelihood of preference for reflective observation and abstract conceptualisation.

We suggested that more individualist cultures would demonstrate a preference for concrete experience and reflective observation. The latter was due to the assumption that active experimentation should be properly thought over before the next step is made. We found statistical evidence that the most individualist cultural sub-group demonstrated the highest preference for concrete experience and reflective observation, which supported our initial suggestion.

Contrary to Joy and Kolb's (2009) findings, we observed a fixed pattern of a proportional decrease of preference for abstract conceptualisation along with the increase of uncertainty avoidance. Concrete experience was desired by the lowest UAI bands but those with a higher degree of uncertainty measured even stronger preference than that. A preference for transforming experience through the mode of active experimentation over reflective observation was found in low UAI countries and the opposite trend in the high UAI, which corresponds to the empirical evidence found by Joy and Kolb (2009).

Based on the empirical evidence we found that the degree of masculinity has a relatively moderate impact on the process of transforming information and a more significant influence on grasping information which appeared to be in line with Joy and Kolb (2009), who identified similar relation between assertiveness (the GLOBE Project equivalent dimension of Hofstede's Masculinity) and learning styles, on contrary to their hypothesised statement. 
Our observation study did not provide evidence of an association between long-term orientation and the preference for grasping information. Despite the statistical significance of our assumption about the relationship between long-term orientation and reflective observation, there was no proof of its direct impact on the preference for transforming experience, as proved by the empirical results in the study of Joy and Kolb (2009).

Implications for practice

Experiential Learning Concept in teaching culturally diverse students Kolb's learning cycle could be summarised as do, review, develop and implement, (Thompson, Chapman 2008-2013). New experiences (doing things) should be observed and reflected upon (reviewing the experience), which should lead to abstract concepts and conclusions (developing ideas), and these conclusions are consequently tested in practice through new experiences (implementation of ideas). The main concept of Kolb's Experiential Learning Theory - its model, cycle, and styles, give educators an instrument to examine the processes of grasping and transforming information by students. Creating and implementing appropriate study programmes in higher education institutions can increase students' productivity for better learning results and establish encouraging education environment.

Independent learning Experiential learning suggests that students can learn independently through reflecting on their personal experiences, so the teacher's role should be a subtle facilitator of the intellectual activities through interdisciplinary incorporation of reflective practice like reflective essays, class discussions, keeping personal diaries and other activities in which students can take their time in patience for objective and careful judgment.

Cultural awareness Developing cultural awareness modules for both students and teachers might be integrated into the curriculum and the institutional training programmes through self-assessment tests, relevant discussions, and engaging activities. All these facilitate a climate of cooperative learning and establish a "psychologically safe" (Powell, Kusuma-Powell 2015) environment for the individual learner.

Experiential learning strategies for teaching The class activities suggested by Montgomery and Groat (1998) supported Kolb's concept of the Divergent and Accommodative style, which relies on acquisition of information through feelings (motivational stories), group discussions of a common experience, self-assessment tests, common experience of new things and shared emotions. All these focus on interpersonal relationships and are said to be typical for the service professions.

Mehigan (2005) and other scholars in the field, suggested the creation of an individual "strategy toolbox" of teaching materials based on research strategies 
for various learning styles. They should be revised, regrouped, added up and validated throughout one's teaching practice in order to find an optimised balance for creating an environment which stimulates the development of the less preferred learning modes of students.

Conclusions

The results of this study provided evidence of a significant impact of culture on students' preference for grasping information through concrete experience. It was found that the process of transforming information through active experimentation over reflective observation was only partially affected by culture. Personality traits and choice of the education field are highly likely to have the most influence on processing information.

Based on the above, we can summarise that the main factors affecting individual preferences for learning styles are cultural characteristics, personality traits, and educational specialisation. The cultural impact appeared to be the most influential on students' inclination to concrete experience, and the professional specialisation to reflective observation, which identified a distinct preference for divergent thinking. Our analysis of the cultural impact on learning proved Power Distance and Uncertainty Avoidance to have the most significant effect on perception and processing of information.

The Experiential learning model can be of help for higher education institutions to create an environment which gives an opportunity to international students for adequately comprehensive learning process through the application of specific approaches which best suit culturally diverse cognitive skills and expectations not only of the Divergent and Accommodative learners but also he Assimilative and Convergent types.

\section{Limitations of the study}

We acknowledge that the results of the study might be limited in terms of the size of the cultural groups' sub-samples, and particularly, the number of cases representing more individualist cultures for a better distinction between collectivist and individualist values. Another limitation can be related to potential perceptual bias, due to the English language terminology used in the Learning Style Inventory.

\section{Recommendations for future study}

Further empirical validation of all cultural dimensions, including the Indulgence versus Restraint, will bring for better understanding and a deeper analysis of the association between culture and learning. The sixth dimension relates to freedom of speech, personal happiness and the feeling of control over one's 
own life, which is highly likely to affect cognitive skills and learning styles preferences.

Further comparison of the relationships between personality traits, cultural dimensions and learning styles of a bigger sample size would be beneficial for higher education institutions for more thorough identification of the factors affecting students' performance and learning outcomes.

\section{References:}

Barmeyer 2000: Barmeyer C. I. Interkulturelles Management und Lernstile. Frankfurt/ New York: Campus Verlag.

Cohen et al. 2004: Cohen E., Brody C., M. Sapon-Shevin. Teaching Cooperative Learning. Albany: State University of New York Press.

Fridland 2002: Fridland G. H. Adult Learning Styles and Cultural Backgrounds: A Comparison of the Learning Style Preferences of American Teachers of English as a Second Language and Chinese Teachers of English as a Foreign Language. Unpublished doctoral dissertation. University of Memphis, TN.

Hofstede 1980: Hofstede G. Culture's Consequences: International Differences in WorkRelated Values. The University of Michigan: SAGE Publications.

Hofstede 2001: Hofstede G. Culture's Consequences: International Differences in Workrelated Values. Thousand Oaks, CA: Sage, (revised Ed.)

Hofstede et al. 2010: Hofstede G., Hofstede G., M. Minkov. Cultures and Organizations. 3rd ed. New York: Mc Graw-Hill.

Holtbrügge, Mohr 2010: Holtbrügge D., A. Mohr. Cultural Determinants of Learning Style Preferences. Academy of Management Learning \& Education, 9(4), pp.622-637.

Hoppe 1990: Hoppe M. A Comparative Study of Country Elites: International Differences in Work-related Values and Learning and Their Implications for Management Training and Development. University of North Carolina at Chapel Hill.

Jaju et al. 2002: Jaju A., Kwak H., G. M. Zinkhan. Learning Styles of Undergraduate Business Students. A Cross-Cultural Comparison between the US, India and Korea. Marketing Education Review. 12(2), 49-60.

Joy, Kolb 2009: Joy S., D. Kolb. Are There Cultural Differences in Learning Style? International Journal of Intercultural Relations. Elsevier.

Kolb 1984: Kolb, D. A. Experiential Learning: Experience as the Source of Learning and Development. Prentice-Hall, Inc., Englewood Cliffs, N.J.

Kolb's Learning Style Inventory: Kolb's Learning Style Inventory. Stanford.edu. $<$ https:// aim.stanford.edu/wp-content/uploads/2013/05/Kolb-Learning-Style-Inventory.pdf > Accessed 26 April 2017].

Kolb, Kolb 2005: Kolb A., D. Kolb. Learning Styles and Learning Spaces: Enhancing Experiential Learning in Higher Education. Academy of Management Learning \& Education.

Lum, Bradley, Rasheed 2011: Lum L., Bradley P., N. Rasheed. Accommodating Learning Styles in International Bridging Education Programs. Higher Education, Skills and Work-Based Learning. 1(2), 147-168. 
Mehigan 2005: Mehigan K. The Strategy Toolbox: A Ladder to Strategic Teaching. - The Reading Teacher. 58(6), 552-566.

Montgomery, Groat 1998: Montgomery S., L. Groat. Student Learning Styles and Their Implications for Teaching. - The Center for Research on Learning and Teaching. 10, 4-5. The University of Michigan. 4-5.

Powell, Kusuma-Powell 2015: Powell W., O. Kusuma-Powell. Overcoming Resistance to New Ideas. - Phi Delta Kappan. 96(8), 66-69.

Sheehan, Kearns 1995: Sheehan M., D. Kearns. Using Kolb: Implementation and Evaluation of Facilitation Skills. - Industrial and Commercial Training. Vol.27. Issue: 6, 8-14. Emeraldinsight. 8-14.

Socscistatistics.com.: Socscistatistics.com. One-Way ANOVA Calculator. <http://www. socscistatistics.com/tests/anova/Default2.aspx $>$ [Accessed 12 June 2017].

Thompson, Chapman 2008-2013: Thompson M., A. Chapman. Concept and Principles of Experiential Learning Activities MTA International, 2008-2013. Businessballs.com. $<$ http://www.businessballs.com/experiential_learning.htm > [Accessed 21 Aug. 2017].

Yamazaki 2005: Yamazaki Y. Learning Styles and Typologies of Cultural Differences: A Theoretical and Empirical Comparison. - International Journal of Intercultural Relations. 29(5), 521-548. 